\title{
Influencing Factors in the Success of Agricultural Crowdfunding
}

\author{
Yang Li ${ }^{1}$, Jieyan Song ${ }^{1}$, Yanan Shao ${ }^{*}$ \\ ${ }^{1}$ School of Economics and Management, Lanzhou Jiaotong University, China \\ *corresponding author
}

Keywords: Agricultural Crowdfunding; Poverty Alleviation; Responsible Consumption

\begin{abstract}
As a new agricultural financing method, agricultural crowdfunding has great development potential. Based on signal theory, this paper took the Longnan Crowdfunding Poverty Alleviation Competition as an example, and constructed a Multivariable Linear Regression Model for empirical analysis by adding responsible consumption factors. The results show that: (1) the number of supporters in the interaction information has a significant positive effect. (2)the use of videos and the return level in the project information have a significant positive effect; the target amount has a significant negative impact; while the number of pictures has no significant effect.(3) poverty alleviation propaganda and special family factors in responsible consumption have a significant positive influence on financing success.
\end{abstract}

\section{Introduction}

Crowdfunding is an action with essence of financing, wisdom absorption and crowdsourcing, which is composed of sponsors, platforms and investors. It is a new financing method that supports the sponsors' projects by raising funds from the public, and is also an investment method that absorbs social idle funds. In the context of agricultural supply-side structural reform and targeted poverty alleviation, agricultural crowdfunding should receive extensive attention as the application in the agricultural field.

Longnan is subordinate to Gansu Province which located in the northwest of China. In order to get rid of economic backwardness, the municipal government and its subordinate departments, in combination with the situation of difficult financing and slow development of local agriculture, vigorously develop rural e-commerce and agricultural crowdfunding, among which the most representative is the Longnan Crowdfunding Poverty Alleviation Competition. Since launched in February 2016, it has attracted nearly 30,000 active participants, including college-educated village officials, disabled youth, caring entrepreneurs, etc. As a demonstration site of China's e-commerce, Longnan has promoted the development of local agricultural crowdfunding through its own efforts.

Taking Longnan as an example, this paper analyzed the influencing factors in the success of agricultural crowdfunding through quantitative method, and put forward a set of corresponding suggestions.

\section{Literature Review}

\subsection{Responsible Consumption}

"Responsible Consumption" refers to consumers who have a sense of social responsibility, link the realization of own consumption value with the interests of others, social development and national progress, and support products or services which conducive to personal growth, environmental protection, economic development and social stability through selective consumption or other means. "Responsible Consumers" will supervise enterprises to fulfill their social responsibilities, and promote the transformation of consumption concepts and patterns to a healthy and sustainable development.

Starting from the basic definition of responsible consumption, Zhang N. (2012) elaborated the specific content of consumers' responsibility, including responsibility to oneself, responsibility to 
others and responsibility to society [1]. From the perspective of perception factors, Li N. (2014) proved that responsible consumption would affect stakeholders as well as the environment through empirical analysis. Meanwhile, gender and education level would influence responsible consumption to some extent [2]. From the perspective of society, Wang T.R. (2011), Fan X.H. (2015) and Wang C.Y. (2016) proposed that consumers should give consideration to environmental protection, social development and national interests while realizing consumption value [3-5].

\subsection{Initiator, Project and Interaction Information}

Zheng H.C. et al. (2015) conducted an empirical study, and concluded that the education background of sponsors is an important feature reflecting the ability of sponsors and has a significant positive effect on enhancing consumers' investment confidence [6-9]. Huang J.Q. et al. (2017) found that the experience of sponsors can reflect the sponsors' proficiency in the project and also has a positive impact on the financing performance [10-14].

The results of the research on the number of pictures and videos are basically the same: the number of videos and pictures has a significant impact on the crowdfunding projects, which indicates that the projects can shock investors through the display of images, and can achieve the purpose of product promotion through visual attraction [11-12] [15-17]. While a small number of scholars hold that the impact of project picture information on financing is not significant [7] [13] [18-19]. On the other hand, there were different opinions on the target fundraising amount of the project. Gou A.P. and Tian J. (2016) analyzed and pointed out that target amount can promote the attention and fundraising ability of the project [20]. Shan M.Y. et al. (2017) concluded that the financing target and minimum investment amount have a significant negative impact on project success [18]. While Xiao J. et al. (2017), Liu Y.B. Liu F.G. (2017) believed that the setting of financing goal hardly affects the success of financing, while the reasonable setting of price is conducive to the smooth financing of crowdfunding projects [11] [14].

Most scholars have shown that the number of project supporters has the most significant influence on financing success [6] [8-9] [21-22]. Comments can promote information exchange. The increase in the number of comments will make the information more complete and transparent, which is conducive to investors' understanding of the project and real-time follow-up of project progress. In order to promote the success of the project, it is necessary to increase the number of project supporters and project reviews. Meanwhile, a few scholars believed that the number of project reviews has a negative impact on financing performance [20-25]. Gou A.P. and Tian J. (2016) analyzed the correlation between the number of likes and the success or failure of financing, and found that there is a negative correlation between the two [20]. Zhai L.L. (2017) believed that in equity-based crowdfunding, the number of project comments plays a negative regulating role in the impact of the initial investment amount on the actual financing amount of the project [21]. A more detailed summary of the research focus of scholars is shown in Table 1.

Table 1 research focus of scholars

\begin{tabular}{|c|c|}
\hline Factors & The Researchers \\
\hline Education & Zheng, H.C.(2015) Liu, J. (2016)Gong, J.L. (2017)Wu, X.Y.(2015) Wang, Z.P.(2018) \\
\hline Experience & $\begin{array}{c}\text { Zeng, J.H. (2017)Zheng, H.C.(2015) Liu, J.(2016) Xiao, J.(2017) Zhang, M.(2017) Huang, } \\
\text { J.Q.(2017) }\end{array}$ \\
\hline Target Amount & $\begin{array}{c}\text { Gou, A.P.(2016) Liu, Y.B. (2017)Shan, M.Y. (2017)Xiao, J. (2017)Yang, S. (2017)Zhang, } \\
\text { T.D.(2017) Zeng, J.H.(2017) Huang, J.Q.(2017) }\end{array}$ \\
\hline Price Setting & Zhang, T.D.(2017) Xiao, J.(2017) Huang, J.Q. (2017)Wu, X.Y.(2015) \\
\hline Pictures & $\begin{array}{l}\text { Xiao, J. (2017)Yang, S. (2017)Zhai, L.L. (2017)Zeng, J.H. (2017)Zhang, M. (2017)Huang, } \\
\text { J.Q.(2017) Shao, Z.Y. (2018)Peng, H.F.(2018) }\end{array}$ \\
\hline Videos & $\begin{array}{c}\text { Xiao, J. (2017)Yang, S.(2017) Zeng, J.H.(2017) Huang, J.Q.(2017) Zhang, M. (2017)Shao, } \\
\text { Z.Y.(2018) Peng, H.F.(2018) Shan, M.Y.(2017) }\end{array}$ \\
\hline Supporters & Gou, A.P.(2016) Liu, Y.B.(2017) Xiao, J.(2017) Yang, S. (2017)Shao, Z.Y.(2018) \\
\hline Comments & $\begin{array}{l}\text { Zhai, L.L.(2017) Gou, A.P.(2016) Zhang, T.D.(2017) Xiao, J. (2017) Zhang, M.(2017) Peng, } \\
\text { H.F.(2018) Wang, P.P.(2018) }\end{array}$ \\
\hline
\end{tabular}




\section{Research Hypothesis}

This paper built the model based on signal theory, including initiator information, project information, interaction information, and special family and poverty alleviation promotion factors in the responsible consumption dimension caused by initiator information and project description. The following content of this article analyzed the success of crowdfunding through the four dimensions of analysis.

\subsection{Responsible Consumption}

Responsible consumption refers to a consumption behavior that combines consumption with social responsibility and promotes social progress. Poverty alleviation is the combination of consumption and social cause, which is the embodiment of responsible consumption.

The sponsor's special family and poverty alleviation mainly refer to whether the sponsor is from a poor family, so as to judge that whether the sponsor can arouse the investors' psychology of responsible consumption. In conclusion, the following hypotheses can be proposed:

H1-1: the sponsors' special family has a positive impact on financing success;

H1-2: poverty alleviation has a positive impact on financing success.

\subsection{Initiator Information}

In the current research, initiator information mainly refers to the factors that reflect the initiators' ability which mainly includes: the identity of the sponsors, social relations, invested in others or not, education background, experience, etc. The above experience will increase the overall control of the project, the familiarity of each link and the confidence of consumers.

The education background of the sponsors can reflect the sponsors' own ability and the learning ability of new ideas or things. Good education can promote the learning and control ability of crowdfunding as well as enhance the confidence of employees or consumers. Therefore, the hypotheses are as follows:

H2-1: the sponsors' experience has a positive impact on financing success;

$\mathrm{H} 2-2$ : the sponsors' education background has a positive impact on financing success.

\subsection{Project Information}

The crowdfunding information displayed by the sponsors on the crowdfunding platforms includes the number of pictures, videos, target amount setting and price setting. The detailed information enables investors to fully understand the project and helps sponsors achieve the purpose of attracting funds.

The reasonable setting of the price range provides investors with more choices, enabling investors with different risk preferences to choose the investment amount of different grades according to their own conditions, as a result, increasing the number of investors and the success rate of financing. The reasonable setting of target amount depending on the amount of money required and the potentiality of projects is conducive to the success of financing and the increase of investors' confidence, while too small amount will make investors doubt the quality of the project. The quantity of pictures and the availability of videos can make investors understand and follow up the project in a more direct way, and accordingly, make reasonable investment decisions. In conclusion, the following hypotheses can be proposed:

H3-1: the reasonable price setting has a positive impact on financing success;

H3-2: the reasonable setting of target amount has a positive impact on the success of financing;

H3-3: the number of pictures has a positive impact on financing success;

H3-4: the availability of videos has a positive impact on financing success.

\subsection{Interaction Information}

After the launch of crowdfunding projects, the sponsors and investors communicate and interact with each other in a variety of ways, including comments, replies to comments, supporters, number of updates to the project, etc. Information exchange enables investors to follow up the progress of 
the project in real time and enhances investors' investment confidence.

The number of supporters reflects the attractiveness of the project. Investors tend to be influenced by others and resulting in a herd effect, so it has a direct impact on the amount of financing. Therefore, in order to promote the success of the project, it is necessary to attract as many supporters as possible. Comments and replies can reflect the interaction between project sponsors and investors, shorten the distance between each other while promoting the project, build trust with investors, and drive investors to make a secondary investment. Through the detailed description of the project, investors can understand the basic contents of the project, such as the type of project products and the region information. In conclusion, the hypotheses are as follows:

H4-1: the number of supporters has a positive impact on financing success;

H4-2: comments and replies have a positive impact on financing success;

H4-3: the number of words in the project description has a positive impact on financing success.

\section{Empirical Analysis}

\subsection{Data and Variable}

The data of this paper came from the material of the Longnan Crowdfunding Poverty Alleviation Competition from 2016 to the present through using network collection tool. Since the platform only published the data of successful projects, we supplemented the data of e-commerce poverty alleviation projects in Huanxian, and obtained a total of 683 pieces of items. Through data cleansing, six ones with the target fund less than 500 and three ones with large outliers were deleted, as a result, 674 ones of data were finally obtained. It should be noted that this paper dealt with the target amount and the raised funds in the sample data by logarithmic processing in order to avoid heteroscedasticity and other problems.

Based on the preliminary analysis of the data, this paper selected 11 main influencing factors as explanatory variables from four dimensions which are showed in Table 2:

Table 2 variable description

\begin{tabular}{|c|c|c|}
\hline Dimension & Explanatory Variable & Variable Description \\
\hline \multirow[t]{2}{*}{ Initiator Information } & experience & Whether sponsor has launched or not(1=yes, $0=$ no) \\
\hline & education background & Education level of project sponsors ( $1=$ college, $0=$ others $)$ \\
\hline \multirow[t]{4}{*}{ Project Information } & pictures & The number of images in the project description \\
\hline & videos & Is there any videos in the introduction $(1=$ yes, $0=$ no) \\
\hline & target amount & sponsor's expected project funding \\
\hline & return level & The grade division of return \\
\hline \multirow[t]{3}{*}{ Interaction Information } & supporters & Number of supporters of the project \\
\hline & description words & The number of words used to describe when it is initiated \\
\hline & comments and replies & The number of interactions with investors after initiated \\
\hline \multirow{2}{*}{$\begin{array}{l}\text { Responsible } \\
\text { Consumption }\end{array}$} & poverty alleviation & Whether related words are included or not(1=yes, $0=$ no $)$ \\
\hline & special family & Is sponsors ordinary or poor $(1=$ special, $0=$ ordinary $)$ \\
\hline
\end{tabular}

\subsection{Empirical Model}

Due to this paper studies the influencing factors in the success of agricultural crowdfunding, so Multivariable Linear Regression Model is used for econometric analysis. And the research samples are all projects with successful financing, that is, the value of financing achievement rate is equal to or greater than $100 \%$. Then the specific model is as follows:

$$
\begin{aligned}
\text { FCR } & =\beta_{0}+\beta_{1} \text { lngoal }+\beta_{2} \text { lnsupporters }+\beta_{3} \text { lncomments } \\
& +\beta_{4} \text { videos }+\beta_{5} \text { pictures }+\beta_{6} \text { experience }+\beta_{7} \text { family } \\
& +\beta_{8} \text { poverty }+\beta_{9} \text { education }+\beta_{10} \text { words }+\beta_{11} \text { level }+\varepsilon
\end{aligned}
$$




\subsection{Regression Analysis}

The data in this paper belong to the cross-sectional data sets. Therefore, before the regression analysis, the Multicollinearity Test was carried out by using robust standard. It is further known that Mean VIF $=1.66<10$, that is, there is no collinearity. Conventionally, the closeness of variables is measured by Correlation Analysis. All variables passed the correlation test, and there is no mutual influence among variables. Therefore Multiple Regression can be carried out.

Table 3 regression analysis

\begin{tabular}{|c|c|c|c|c|c|c|c|}
\hline Variables & Coefficient & SE & t Stat & P-value & [95\% Conf & Interval] & Sig \\
\hline Fundraising Goal & -0.364 & 0.084 & -4.34 & 0.000 & -0.529 & -0.199 & $* * *$ \\
\hline Comments & 0.011 & 0.008 & 1.29 & 0.196 & -0.006 & 0.027 & \\
\hline Description Words & 0.100 & 0.078 & 1.28 & 0.201 & -0.053 & 0.253 & \\
\hline Support Record & 0.000 & 0.000 & 2.92 & 0.004 & 0.000 & 0.001 & $* * *$ \\
\hline Pictures & 0.355 & 0.244 & 1.45 & 0.147 & -0.125 & 0.834 & \\
\hline Return Level & 0.131 & 0.046 & 2.86 & 0.004 & 0.041 & 0.220 & **** \\
\hline Videos & 0.123 & 0.050 & 2.48 & 0.014 & 0.025 & 0.220 & ** \\
\hline Special Family & 1.463 & 0.254 & 5.76 & 0.000 & 0.964 & 1.962 & **** \\
\hline Poverty Alleviation & 1.410 & 0.239 & 5.91 & 0.000 & 0.942 & 1.879 & **** \\
\hline Education & 0.642 & 0.270 & 2.38 & 0.018 & 0.112 & 1.172 & $* *$ \\
\hline Experience & 0.419 & 0.224 & 1.87 & 0.062 & -0.021 & 0.859 & * \\
\hline Constant & 1.350 & 0.606 & 2.23 & 0.026 & 0.160 & 2.541 & $* *$ \\
\hline \multicolumn{2}{|c|}{ R-squared } & 0.323 & \multicolumn{3}{|c|}{ Number of obs } & 674.000 & \\
\hline \multicolumn{2}{|l|}{ F-test } & 19.199 & \multicolumn{3}{|c|}{ Prob $>F$} & 0.000 & \\
\hline
\end{tabular}

It can be seen from Table 3 that the sponsors' special family and poverty alleviation factors are significant at the level of $1 \%$. Responsible consumption motivates consumers to invest for the purpose of helping individuals find employment or society out of poverty which shows a significant positive impact on the success of the project. In view of this, it can be proved that the hypothesis of H1-1 and H1-2 are both true.

The sponsors' education is significant at the level of 5\%, indicating that the sponsors' academic background can reflect the sponsors' learning ability for new ideas and new things. The experience of sponsors is basically significant at the level of $10 \%$, indicating that the sponsors could improve the overall control ability of the project and increase the confidence of investors through project experience. Moreover, with relevant professional skills and entrepreneurial experience will also make sure that sponsors deal with the problems in the process of crowdfunding more appropriately. Therefore, the hypotheses of H2-1 and H2-2 should be accepted.

Return level and videos are significantly positive correlation on the level of $1 \%$ and $5 \%$ respectively, while the target price is significantly negative correlation. This shows that: a reasonable price setting can improve the success rate of the project; the description of the videos can improve the understanding and the authenticity of the project, meanwhile, increase investors' confidence in the project; multiple choices of return level allow investors with different risk preferences to invest according to their own circumstances. In view of this, hypothesis of H3-1, H3-2, H3-4 are all true. However, the number of pictures is not significant, so hypothesis of H3-3 should be rejected.

The number of supporters is significantly related at the level of $1 \%$, it means that through the interaction between the sponsors and investors, the trust of each other and understand the real-time situation of the project could be guaranteed. So hypothesis of H4-1 should be accepted. On the contrary, the number of comments is not significant, mainly due to the repeated comments and malicious reviews by relatives or friends; and the factor of description words is also not significant. As a result, hypothesis of H4-2 and H4-3 should be rejected.

At last, this paper conducted Robustness Test on the research results. And the analysis consistent with the overall data results shows that the model is robust and reliable. 


\section{Suggestions}

Through the analysis of this article, suggestions are given from the following three aspects:

(1) Use emotion to drive investment

Due to the excessive number of crowdfunding products and the similar quality, it is necessary to have something new and unique to stand out from the numerous products. The design of the title and content of crowdfunding could take the form of "combination of crowdfunding and poverty alleviation" or "combination of crowdfunding and feelings". In particular, special groups need to make good use of their own strengths and avoid weaknesses. What needs to be caught is to get the care of social public and use emotion to stimulate investment through the publicity of personal special experience. But it is necessary to pay attention to copywriting and consider of the meaning of the project itself, rigid reference is not advisable.

(2) Improve the quality of project information

A single platform, common text description, and simple picture promotion cannot effectively attract the attention of investors, which is not conducive to the success of fundraising. Therefore, it is crucial to expand the forms of publicity and enhance the public's understanding of crowdfunding projects. For example: (1) through short videos of crops to ensure the authenticity and timeliness of projects; (2) publicity can be carried out through WeChat Official Account, WeChat Moments, Micro-blog Hot Search List and other channels to expand the publicity radius of projects; (3) regarding to the return setting of the project, the acceptance range of investors and the multi-level reasonable setting of price range should take into consideration, the types of returns of different grades should also be enriched on the basis of focusing on the nature of the project itself.

(3) Pay attention to the feedback of interaction information and the return visit

By effectively screening project reviews, thus making the quality ones will be placed at the top, and through the project update to deal with duplicate comments. Rewards can be used to encourage followers to make good reviews and increase the credibility of the project. Focus on the interaction with investors and the return visit after the completion of crowdfunding to understand their final satisfaction degree to the crowdfunding project. What needs to do afterwards is to give appropriate compensation to investors who are not satisfied with the return product. And it is necessary to learn from it and gain useful experience so as to improve the deficiencies in the future projects.

\section{Acknowledgements}

The authors would like to acknowledge the financial supports provided by Social Science Foundation of Gansu Province, China(Grant No.YB077 \& Grant No.YB076) and Educational Commission of Gansu Province, China(Grant No. 2019B-065 \& 2018F-08).

\section{References}

[1] Zhang, N. (2012) Analysis on Consumer Responsibility. Ability and Wisdom, 23, 4-5.

[2] Li, N. (2014) Influence and Countermeasures of Personal Emotion on Social Responsible Consumption Behavior. Journal of Commercial Economics, 32, 55-57.

[3] Wang, T.R. Li, J.F. (2011) Significance and Path Selection of Advocating "Responsible Consumption". People's Tribune, 08, 116-117.

[4] Fan, X.H. (2015) Sustainable Consumption Model from the Perspective of Social Responsibility of Consumption. China Collective Economy, 19, 14-15.

[5] Wang, C.Y. Wu, B. (2016) Connotation, Motivation and Realization Path of Social Responsible Consumption Education in Chinese Context. Journal of Commercial Economics, 15, 135-136.

[6] Zheng, H.C. Huang, Y.M. Wang, T. Chen, D.Y. (2015) Influencing Factors of Financing Performance of Equity Crowdfunding for Innovative Projects. China Soft Science, 01, 130-138.

[7] Gong, J.L. (2017) Analysis of Farmers' Willingness to Agricultural Crowdfunding under F2F 
Model -- A Case Study of Xiaogan, Hubei. Finance Economy, 03, 3-36.

[8] Wang, Z.P. (2018) Research on Incentive Crowdfunding Users' Willingness in Continuous Participation Based on Expectation Confirmation Theory. Soft Science, 10, 135-139.

[9] Wu, X.Y. Zhou, J.B. (2015) Influencing Factors of Public Participation in Crowdfunding Investment Decision. Science \& Technology Progress and Policy, 24, 12-16.

[10] Huang, J.Q. Huang, X.F. Yin, G.P. (2017) Influencing Factors and Prediction Model of Financing Success of Crowdfunding Project. China Soft Science, 07, 91-100.

[11] Xiao, J. Zhu, H.Y. Jia, J. (2017) Comparative Study on Agricultural Crowdfunding Platform and Optimal Choice. Rural Economy, 01, 82-88.

[12] Liu, J. Liu, Y.J. (2016) Research on Financing Demand and Influencing Factors of Small and Micro Enterprises. Journal of Hunan University of Science \& Technology (Natural Science Edition), 31(04), 114-121.

[13] Zeng, J.H. Li, L.H. (2017) Empirical Research on the Influence of Quality Signal on the Success of Agricultural Crowdfunding Project Financing. Social Sciences in Guangxi, 06, 78-83.

[14] Liu, Y.B. Liu, F.G. (2017) Empirical Study on Influencing Factors of Incentive Crowdfunding Performance. Modern Business, 02, 103-104.

[15] Yang, S. (2017) Influencing Factors on the Success of Commodity Crowdfunding Projects. Wuhan Finance, 10, 41-45.

[16] Zhang, T.D. Hu, Y.Y. (2017) Analysis on Influencing Factors of Crowdfunding Project Financing Efficiency. Soft Science, 03, 16-20.

[17] Shao, Z.Y. Fu, J.Q. (2018) Analysis on Influencing Factors of Crowdfunding Performance. Hebei Enterprises, 08, 35-36.

[18] Shan, M.Y. Li, H. Liu, X.H. (2017) Influencing Factors of Crowdfunding on "Internet + Agricultural Products" Based on TPB Theory. Science and Technology Management Research, 02, 235-240.

[19] Peng, H.F. Lin, C. (2018) Empirical Evidence Based on "Crowdfunding Network" from the Perspective of Social Capital. China Economic Studies, 02, 83-101.

[20] Gou, A.P. Tian, J. (2016) Related Factors Affecting the Fundraising Ability of Projects in Public Crowdfunding. Economy and Management, 10, 139-142.

[21] Zhai, L.L. Zhang, M. Ding, X.C. (2017) Influencing Factors of Financing Performance of Equity Crowdfunding: An Empirical Study Based on Renren.com. Journal of Wuhan University of Technology (Information \& Management Engineering), 05, 569-574.

[22] Chen, Y.J. Ni, N.X. Gou, X.J. (2015) Influencing Factors of the Success of Crowdfunding Projects in the Context of Innovation and Entrepreneurship. Shanghai Journal of Economics, 11, 12-19.

[23] Wang, P.P. Han, Y.J. Liu, N.X. Dong, K.X. (2018) The Influence of Webpage Interaction and Promoter's Qualification on Agricultural Crowdfunding Project Financing Performance. Science \& Technology Progress and Policy, 03, 1-7.

[24] Zhou, J.B. (2016) Influencing Factors of Choosing Internet Crowdfunding for Entrepreneurial Projects. Science \& Technology Progress and Policy, 17, 31-36.

[25] Zhang, M. Ding, X.C. (2017) Analysis of Influencing Factors on the Success of Return-based Crowdfunding Projects Based on Indiegogo. China Circulation Economy, 03, 70-74. 